



Пátpa, Máıo 2010
Bulletin of the Geological Society of Greece, 2010

Proceedings of the 12th International Congress

Patras, May, 2010

\title{
MODERATE MAGNITUDE EARTHQUAKE SEQUENCES IN CENTRAL GREECE (FOR THE YEAR 2008)
}

\author{
Roumelioti Z. ${ }^{1}$ and Kiratzi A. ${ }^{2}$ \\ ${ }^{1}$ Archaeologikou Mouseiou 46, 54641 Thessaloniki, Greece, zroum@auth.gr \\ ${ }^{2}$ Department of Geophysics, Aristotle University of Thessaloniki, P.O. Box 352-1 Thessaloniki, Greece, \\ Kiratzi@geo.auth.gr
}

\begin{abstract}
The small-to-moderate magnitude earthquake sequences offshore NE Evia island (Mantoudi, October 2008) and in central Greece, to the NW of the town of Amfiklia (December 2008) are studied in terms of their source parameters and strong shaking in nearby populated areas. Moment tensors of the strongest events of the sequences, their seismogenic faults and the distribution of slip on them are sought through the inversion of regional broadband waveforms. We then apply a forward modelling technique, which incorporates synthetic Green's functions calculated for a $1 D$ velocity model, previously proposed for the broader studied area, to get a first-order evaluation of the distribution of strong ground shaking around the hypocenters. The Mantoudi earthquake sequence is found to be associated to an offshore NE$S W$ trending normal fault that dips to the $N W$, with a considerable dextral strike-slip component. The Amfiklia earthquake sequence is related to a pure normal, $E$-W trending fault which dips to the south. This conclusion is drawn by both the distribution of aftershocks and the inversion process for the computation of slip on the seismogenic fault of the strongest event of the sequence $\left(M_{w} 5.1\right)$. Forward modelling of strong ground shaking based on event-specific moment tensor and slip distribution indicates low levels of expected ground motion in accordance with the limited observed damage.
\end{abstract}

Key words: moment tensor, slip distribution, shake map, seismicity, Greece.

\section{Introduction}

Earthquake swarms and seismic sequences of moderate magnitude earthquakes are rarely responsible for significant damage in the natural and built environment of modern cities. However, they often have a phychological impact on the populations of the broader areas of their occurrence and are of scientific interest as their study can provide information on the seismotectonics and their data can be used to test and validate real and near-real time seismological applications. Herein, we study two earthquake swarms that occurred in central Greece, the first one offshore NE Evia Island and the second one close to the town of Amfiklia, during the year 2008. We present moment tensor solutions for the strongest events of the sequences and slip distributions for the two main events. Specific slip distributions are further incorporated into forward modelling of strong ground motion to provide shake maps for the broader epicentral areas. 




Fig. 1: Moment tensor solution for the 14 October 2008, GMT 02:06 earthquake (No 1 in Table 1). Used stations provide the best azimuthal coverage of the epicentre without over-weighting any azimuth. For each station waveform fit between observed (continuous lines) and synthetic (dashed lines) vertical, tangential and radial components are shown (left). Solution parameters are summarized in the right part of the figure.

\section{The $\mathbf{1 4}$ October $\mathbf{2 0 0 8}$ moderate magnitude sequence offshore NE Evia Island (Aegean Sea)}

\subsection{Seismotectonic regime}

On October 14, 2008 a moderate magnitude $\left(\mathrm{M}_{\mathrm{w}}\right.$ 5.1) sequence initiated offshore the NE coast of Evia Island which faces the Aegean Sea. Evia Island lies in the transition zone from strike-slip faulting to the east, due to the strands of the North Anatolian Fault (NAF) that enter to the Aegean Sea, to normal faulting to the west in central Greece. From this point of view, its pattern of deformation is always interesting, to seek for example the mode in which the shear motion from the east is crossing into mainland Greece.

\subsection{Moment tensors of the October 2008 stronger earthquakes}

Moment tensors of the stronger events of the sequence were computed by the Time-Domain Moment Tensor inversion method (TDMT_INV) developed at the Berkeley Seismological Laboratory (Dreger, 2002, 2003). In the specific method full broadband waveforms of the three recorded components of motion are low-pass filtered and inverted to derive the moment tensor. In the inversion procedure theoretical Green's functions are required to model the propagation of the seismic waves.

Data used in all herein applications were gathered through the Hellenic Unified Seismological Network (HUSN) of Greece. Prior to the inversion procedure, waveforms were band-pass filtered between $0.02-0.08 \mathrm{~Hz}, 0.05-0.08 \mathrm{~Hz}$ or $0.05-0.10 \mathrm{~Hz}$ depending on the magnitude of each analyzed 


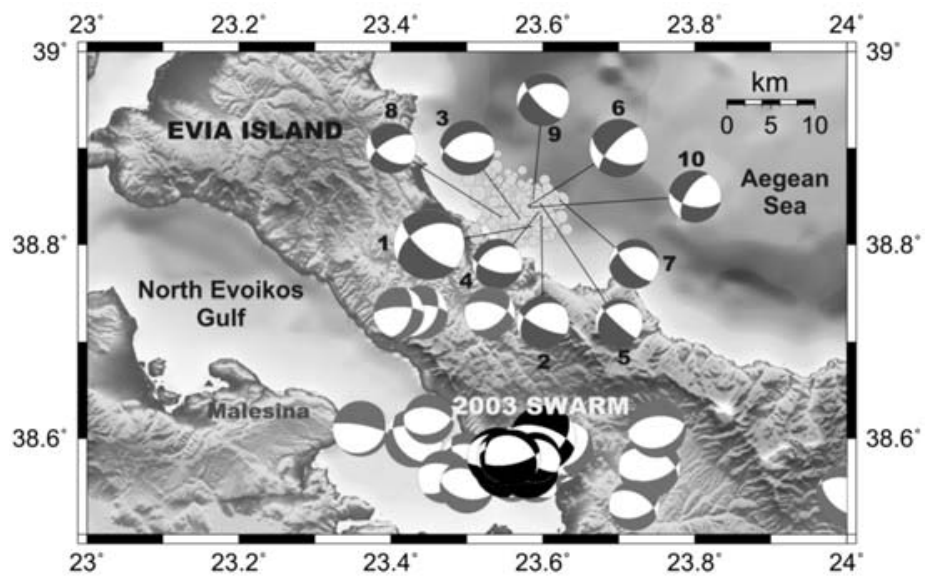

Fig. 2: The 14 October 2008 focal mechanisms (red beach-balls; numbering as in Table 1) and previous focal mechanisms determined by waveform modelling available for Evia Island (Hatzfeld et al., 1999; Benetatos et al., 2004; Roumelioti et al., 2010; National Observatory of Athens - http://bbnet.gein.noa.gr). Earthquake epicenter locations are from the on-line catalog of the Aristotle University of Thessaloniki (https://seismology.geo. auth.gr). The 2003 swarm focal mechanisms are depicted in black-and-white colours.

Table 1. Source parameters of the studied events offshore Evia Island (epicentre locations are from the on-line archive of the Department of Geophysics of the Aristotle University of Thessaloniki, http://seismology.geo.auth.gr).

\begin{tabular}{|c|c|c|c|c|c|c|c|c|c|c|c|c|c|c|c|c|}
\hline [0 & 1 & SS & $\begin{array}{l}\text { Lat } \\
\left({ }^{0} \mathrm{~N}\right)\end{array}$ & $\left({ }^{0} \mathrm{E}\right)$ & $\begin{array}{c}\mathrm{h} \\
(\mathrm{km})\end{array}$ & $\begin{array}{c}\mathrm{M}_{0} \\
\times 10^{22}\end{array}$ & $\mathbf{M}_{w}$ & r1 & p1 & $\begin{array}{c}\text { Rake } \\
1\end{array}$ & Str2 & Dip2 & $\begin{array}{c}\text { Rake } \\
2\end{array}$ & & $\begin{array}{l}\text { vd } \\
\text { b) }\end{array}$ & $\begin{array}{l}\mathrm{Vr} \\
(\%)\end{array}$ \\
\hline 1 & & & & 2 & 9 & .1 & & & & & 101 & & & & 7 & 81.5 \\
\hline 2 & & & & & & 0.10 & & 234 & & & 117 & & & & 17 & 80.3 \\
\hline 3 & 1014 & & 827 & 569 & 7 & 6 & & 247 & & & 99 & & & & & 80.2 \\
\hline 4 & 1014 & 03:1 & 833 & 23.594 & & .30 & & 236 & & & 104 & & -6 & & & 83. \\
\hline 5 & 014 & $04: 39$ & .842 & 23.597 & 9 & .1. & & 237 & 24 & 104 & 132 & 04 & -01 & & 2 & 87.5 \\
\hline 6 & 010 & $19: 29$ & 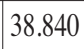 & 23.581 & 政 & 32 & & 22. & 70 & 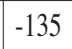 & 114 & & 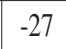 & & 2 & 82.4 \\
\hline 7 & 027 & 10:41 & 846 & 23.623 & 7 & 7 & 5 & 262 & 32 & 137 & 135 & 69 & -66 & & & 87 \\
\hline 8 & 1129 & $06: 43: 18.3$ & 38.829 & 23.545 & . & 0.31 & & 2.0 & & 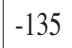 & 124 & 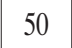 &  & & & 75.5 \\
\hline 9 & 90116 & 01:21:56.9 & 38.848 & 23.587 & 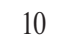 & & & 251 & & 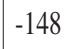 & 136 & 然 & 50 & & 7 & 91.5 \\
\hline 10 & 0331 & 02:20:01.8 & 38.839 & 23.583 & 7 & 0.53 & 3.75 & 211 & 62 & -142 & 101 & 57 & -33 & &  & 80.6 \\
\hline
\end{tabular}

event and thus the signal-to-noise ratio in its waveforms. Synthetic Green's functions for all herein applications were produced using the FKRPROG code of Saikia (1994) and the velocity model of Novotny et al. (2001), which has been successfully used in similar studies of earthquakes of the broader Aegean area (e.g. Benetatos et al., 2004; Roumelioti et al., 2008a, 2010).

We computed moment tensor solutions for ten events (Table 1 summarizes the source parameters of 




Fig. 3: Slip distribution (slip in $\mathrm{cm}$ ) for the October 14,2008; GMT 02:06 Mw5.1 event, onto the fault plane (i.e. the nodal plane that dips to the NW in Fig. 1). The slip area expands almost symmetrically around the adopted hypocenter location (asterisk). Note that the 0 in this figure corresponds to the depth of $9 \mathrm{~km}$ obtained from the MT solution.

the analyzed events). The last three columns summarize quantitative measures for the quality of each computed MT. For further description of the parameters the reader is referred to the original work of Dreger 2002, 2003) within the epicentral area of the 14 October 2008, two of which, however, occurred few months after the burst of the main activity. In Figure 1 we indicatively show the moment tensor solution for the strongest, Mw5.1, event of the sequence. In Figure 2 we show the computed focal mechanisms along with previous known mechanisms of earthquakes (all from waveform inversion) on and around the Evia Island. Clearly normal faulting is prevailing combined with strike-slip motions. For the 2008 events the fault plane for the Mw5.1 event is the one that dips to the NE (see section 2.3), implying dextral strike-slip motion and a slip vector trending $\mathrm{N} 41^{\circ} \mathrm{E}$. The most recent intense seismic activity, prior to the one studied herein, was the 2003 swarm close to the town of Psahna (black coloured beach balls in Figure 1), a rock burst region in Evia, like the town of Mantoudi which was close to the 2008 events.

\subsection{Slip model for the Oct 14, GMT 02:06 Mw 5.1 event}

To obtain the slip distribution model for the GMT 02:06 Mw 5.1 event (Fig. 3) we used the methodology of Dreger and Kaverina (2000) and Kaverina et al. (2002), in which regional distance ground motions recorded on broadband instruments are inverted for slip through a least squares scheme. The applied method requires simplifying assumptions including constant rupture velocity and dislocation rise time and poses slip positivity, seismic moment minimization and smoothing constraints during the inversion procedure.

Both nodal planes were tested as candidate seismogenic (Roumelioti et al., 2008b) as the applied methodology is capable of uniquely determining the causative fault plane of the earthquake and realistically determining the gross characteristics of the slip distribution (both along strike and down dip). These characteristics are adequate to incorporate the major source effect on expected strong ground motions. For the $\mathrm{M}_{\mathrm{w}} 5.1$ event the nodal plane that dips to the NW (that is the one with strike $242^{\circ}$ ) was statistically detected as the fault plane. This implies that the azimuth of the slip vector is $\mathrm{N} 41^{\circ} \mathrm{E}$ and its plunge $21^{\circ}$, in accordance with the direction of the shear motion transferred from the 


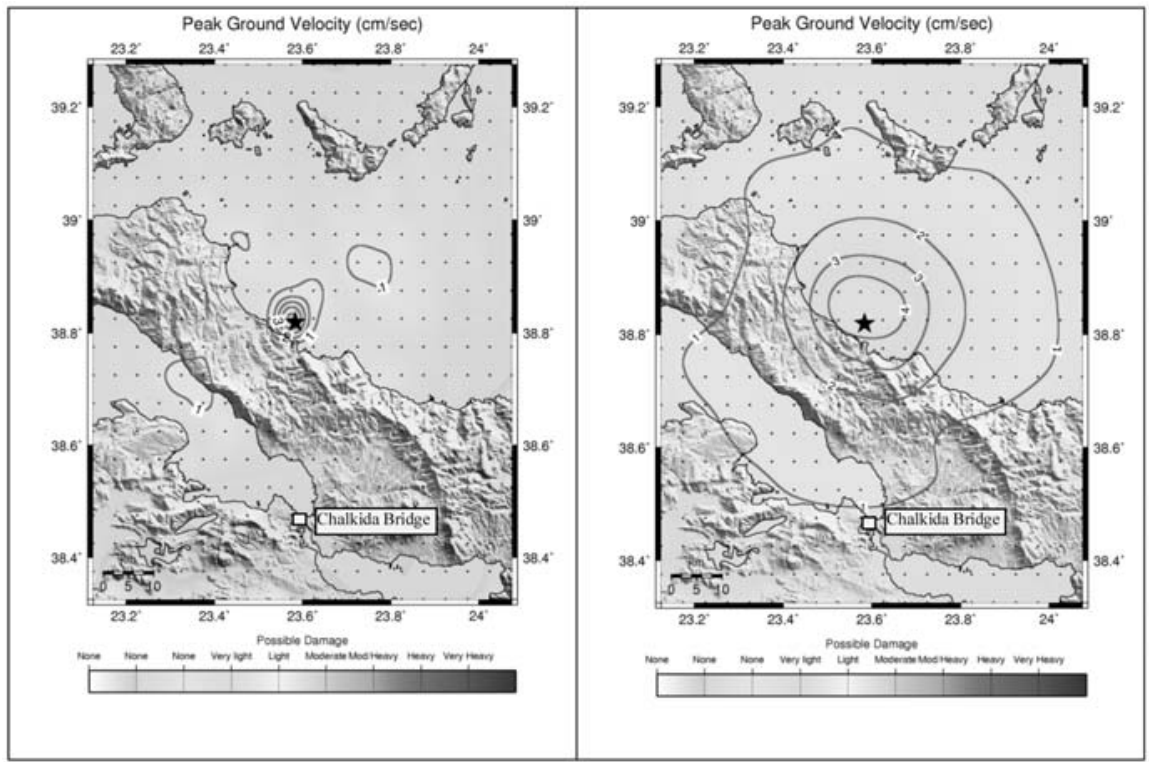

Fig. 4: Left : Distribution of synthetic PGV's for the 14 Oct. 2008 Mw5.1 event, based on the slip model of Fig. 3. Right: Distribution of PGV's obtained using the empirical relations of Skarlatoudis et al. $(2003,2007)$ for comparison.

east (Kiratzi, 2002). Slip appears in one symmetric patch expanding around the adopted hypocenter location. Average slip in the ruptured area is $\sim 4 \mathrm{~cm}$ and peak slip reaches $15 \mathrm{~cm}$ very close to the rupture initiation point.

\subsection{Deterministic Computation of PGV maps (Shake Map) for the strongest Mw 5.1 event}

We incorporated the regionally derived slip model (Fig. 3) in the forward calculation of strong ground motion within a grid $50 \times 50 \mathrm{~km}$ centered at the epicentre location. As in the inversions described in the previous section, for the forward problem we used the code of Kaverina et al. (2002). We computed full velocity waveforms up to $5 \mathrm{~Hz}$ and retrieved their peak values to construct maps with the distribution of the specific strong ground motion measure (Fig. 4a). Details on this part of the applied methodology and relative references are also included in Roumelioti et al. (2008b). Site effects at the nodes of the grid were grossly described based on the topography gradient as suggested by Wald and Allen (2007). For reasons of comparison we additionally computed synthetic PGV values using the empirical relations of Skarlatoudis et al. (2003, 2007) (Fig. 4b). By comparing the two maps in Figure 4 it becomes obvious that peak PGVs in Fig. 4a are concentrated in a smaller region and decay much faster compared to corresponding values in Fig. 4b. The closest observed strong motion record of the specific earthquake was obtained by ITSAK at the Bridge of Chalkida (Figure 4) and PGV was of the order of $0.23 \mathrm{~cm} / \mathrm{sec}$ (N. Theodulidis, personal communication), a value which lies between the two independent evaluations mapped in Figure 4.

\section{The December 2008 Amfiklia Earthquake Sequence}

\subsection{Seismotectonic regime}

On the $13^{\text {th }}$ of December 2008, 08:27 GMT, an earthquake measuring $\mathrm{M}_{\mathrm{w}} 5.1$ occurred at about 10 




Fig. 5: Left: Distribution of epicentres (yellow circles, diameters are analogue to the earthquake magnitude) of the December 2008 Amfiklia sequence. Beach balls for the computed focal mechanisms (Table 2) are also plotted.

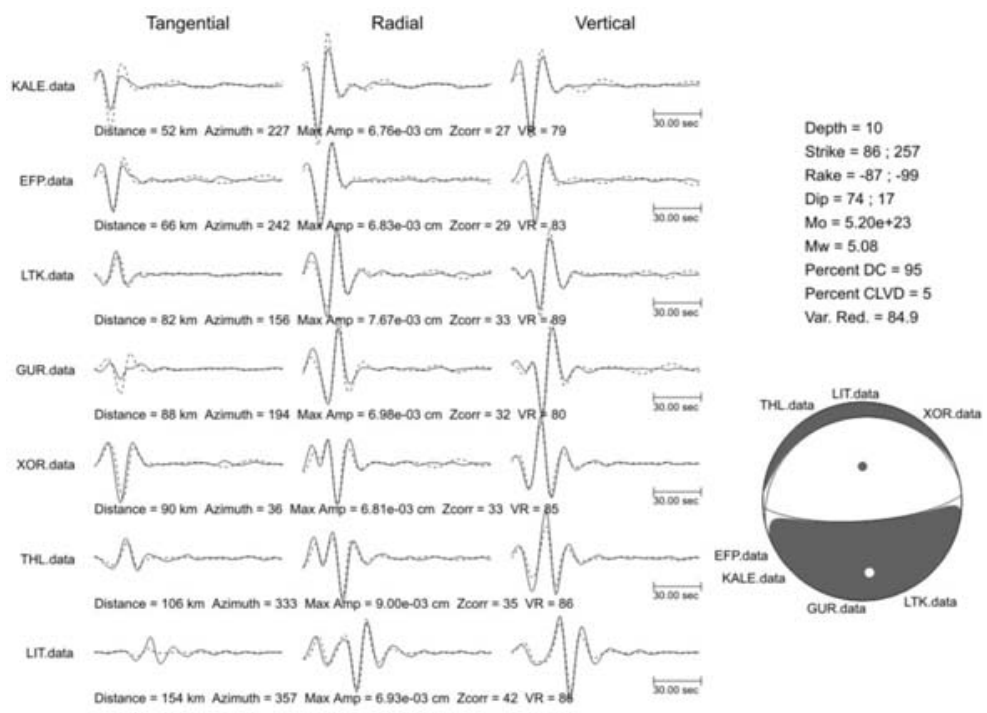

Fig. 6: Moment tensor solution for the 13 December 2008, GMT 08:27 earthquake (No 1 in Table 3). For each station waveform fit between observed (continuous lines) and synthetic (dashed lines) vertical, tangential and radial components are shown (left). Solution parameters are summarized in the right part of the figure.

$\mathrm{km} \mathrm{SE}$ of the town of Lamia in central Greece, close to the small town of Amfiklia (herein the sequence is named after this town). Despite its moderate magnitude the earthquake caused minor damage (mostly cracks and plaster falls) to one church and to more than twenty residences, mostly of rock, in Amfiklia and nearby villages. Limited landslides were also observed and as a consequence traffic in one country road was interrupted for a few hours. Epicenters of this small sequence (Figure 5) are gathered on top of the south facing slope of the topographic high to the north of Amfiklia. For this area there are no reports for significant tectonic structures. Known large faults have been mapped to the north (e.g. Ganas and Papoulia, 2000; Roberts and Ganas, 2000) and dip to the 
Table 2. Focal mechanism parameters of the December 2008 sequence to the NW of Amfiklia. Earthquake epicentre locations are those of the online archive of the Aristotle University of Thessaloniki (http://seismology.geo.auth.gr).

\begin{tabular}{|c|c|c|c|c|c|c|c|c|c|c|c|c|c|c|c|c|}
\hline & D & SS & Lat & $\begin{array}{l}\text { Lon } \\
\left({ }^{0} \mathrm{E}\right)\end{array}$ & $\begin{array}{c}\mathbf{h} \\
(\mathbf{k m})\end{array}$ & $\begin{array}{c}M_{0} \\
\times 10^{22}\end{array}$ & $\mathbf{M}_{\mathrm{w}}$ & r1 & p1 & $\begin{array}{c}\text { Rake } \\
1\end{array}$ & Str2 & p2 & $\begin{array}{c}\text { Rake } \\
2\end{array}$ & & $\begin{array}{l}\text { Clvd } \\
(\%)\end{array}$ & $\begin{array}{l}\mathbf{V r} \\
(\%)\end{array}$ \\
\hline 1 & & & & 576 & 10 & .0 & & & & & & & & & & 840 \\
\hline 2 & & & 17 & 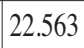 & 7 & & & & & -88 & 257 & & -103 & & & 04.1 \\
\hline 2 & 213 & $15: 54: 40.5$ & 38.712 & 22.624 & 7 & 1 & 0.0 & 112 & 00 & -75 & $2 J 1$ & 10 & -144 & & & 74. \\
\hline
\end{tabular}



Fig. 7: Slip distribution (slip in $\mathrm{cm}$ ) for the 13 December 2008, GMT 08:27 earthquake Mw5.1 event, onto the fault plane (i.e. the nodal plane that dips to the $\mathrm{S}$ in Fig. 5). The slip area expands around and to the west of the adopted hypocenter location (asterisk). Note that the 0 in this figure corresponds to the depth of $10 \mathrm{~km}$ obtained from the MT solution.

north. In this frame, the 2008 sequence appears to be related to a small, antithetic to the known large faults, structure that bounds the Gravia - Amfiklia depression to the north. The occurrence of the 2008 sequence was studied in the frame of the general seismicity of the area by Chouliaras (2009).

\subsection{Moment tensors}

Following the TDMT_INV approach we computed the moment tensors of the largest events of the sequence. Due to the small magnitudes of the events we were capable of obtaining stable inversions for only three events. For reasons of space economy we present the results for only the main event of the sequence (Figure 6); however all detailed solutions are available upon request. Basic parameters of the computed moment tensors are listed in Table 2 and corresponding beach-balls are plotted in Figure 5.

\subsection{Slip distribution}

The slip distribution of the 13 December 2008, GMT 08:27 event was computed by inverting the exact broadband waveforms (and corresponding frequency intervals) previously used to calculate its moment tensor (depicted in Figure 6) to ensure the sufficiency of the employed 1D velocity model. The extracted slip distribution model is shown in Figure 7. Most slip appears concentrated very close to the adopted hypocenter location and the rupture area extends to the WSW of it. Average slip within the ruptured area is $\sim 3.5 \mathrm{~cm}$ while the peak value is $10 \mathrm{~cm}$ and appears at a distance of $\sim 1$ $\mathrm{km}$ to the west of the hypocenter. 


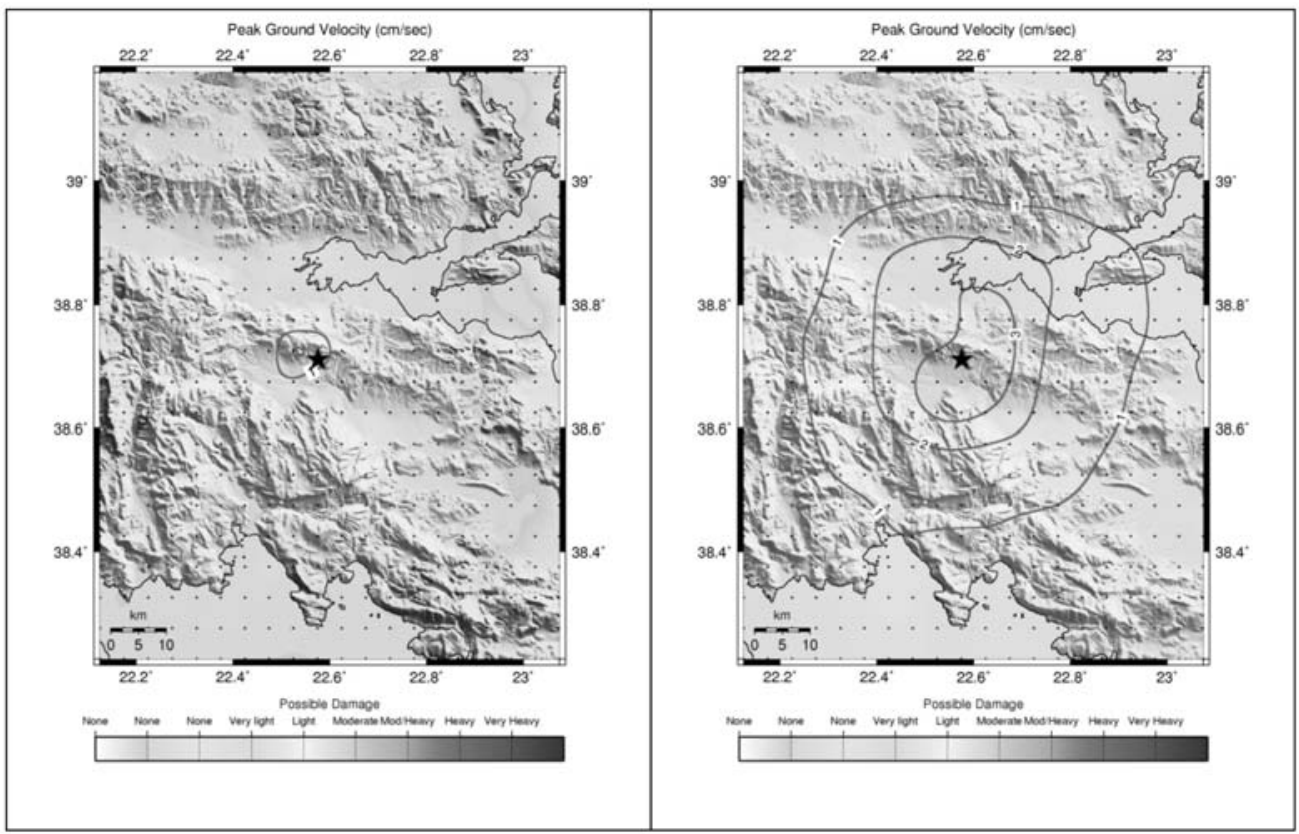

Fig. 8: Left : Distribution of synthetic PGV's for the 13 December 2008, GMT 08:27 event, based on the slip model of Fig. 7. Right: Distribution of PGV's obtained using the empirical relations of Skarlatoudis et al. (2003, 2007) for comparison.

\subsection{Shake maps}

The synthetic PGV map of the 13 December 2008, GMT 08:27 earthquake as derived through forward modelling based on the specific slip distribution of Figure 7 is presented in Figure 8a. In Figure $8 \mathrm{~b}$ the corresponding map based on values computed through appropriate empirical relations (Skarlatoudis et al. 2003, 2007) is also shown for comparison.

\section{Results - Discussion}

No strong earthquake has occurred in Evia Island during instrumental times, and tectonic information from moderate size seismicity, like the one studied herein, is valuable. Previous work (Hatzfeld et al., 1999; Kiratzi, 2002) has shown that the deformation in northern Evia Island is taken up mainly by normal and strike-slip faulting. Depending on the orientation of the activated faults, in respect to the present state stress field, dextral or sinistral horizontal motion is observed. The recent earthquakes showed that an almost N-S extensional field prevails in NE Evia Island with a few strike-slip focal mechanisms, suggesting that this part is mostly affected by the normal faulting system of central Greece.

Regarding the small sequence to the NNW of Amfiklia in central mainland, it is related to an E-W trending normal fault, in accordance with the N-S direction of extension indicated by geodetic and geological data of the broader area (Clarke et al., 1998; Briole et al., 2000; Roberts and Ganas, 2000). However, the specific seismicity is observed on an antithetic to the prevailing faults of the broader area structure. 
Synthetic PGV maps were constructed for both examined main events using a deterministic approach in comparison to empirical strong ground motion relations. Both approaches predict very light or no damage in both applications; however they lead to significantly different PGV distributions with the first one providing lower levels of strong ground motion. Such differences are, in fact, expected in the near fault region of an earthquake where the source effect is significant. This effect is incorporated in the deterministic approach whereas in the empirical relations it is smoothed out during the regression process. For earthquakes of magnitude around 5, such as the ones studied in this paper, the source effect is expected to be hardly observed at distances larger than $20-25 \mathrm{~km}$ from the epicentre. Thus, at larger distances $(>25 \mathrm{~km})$ the differences in the two PGV sets should be sought in the modelling of the attenuation and/or site effects. The only observed strong ground motion record, which was obtained during the 14 October 2008, $\mathrm{M}_{\mathrm{w}}$ 5.1 Mantoudi earthquake, shows PGV which lies between the two independently derived synthetic values. More observed records as well as stronger events are necessary for further validating and improving the herein applied methodology for incorporating the source effect in strong ground motion distributions in the near source region.

\section{Acknowledgments}

We thank Douglas Dreger of the University of California at Berkeley for providing the codes applied herein and for his valuable help. We also thank Athanassios Ganas of the National Observatory of Athens for providing information on the tectonic setting of the Amfiklia sequence and Nikolaos Theodulidis of the Institute of Engineering Seismology and Earthquake Engineering (ITSAK) for informing us on the observed strong motion records of the Mantoudi main event. Maps were produced using the GMT software (Wessel and Smith, 1998). Partial financial support from General Secretariat of Research and Technology (GSRT) of Greece is gratefully acknowledged.

\section{References}

Benetatos C., Kiratzi A., Kementzetzidou K., Roumelioti Z., Karakaisis G., Scordilis E., Latoussakis I. and Drakatos G., 2004. The Psachna (Evia Island) earthquake swarm of June 2003. Bulletin of the Geological Society of Greece, XXXVI (3), 1379 - 1388.

Briole P., Rigo A., Lyon-Caen H., Ruegg J., Papazissi K., Mitsakaki C., Balodimou A., Veis G., Hatzfeld D. and Deschamps, A. (2000). Active deformation of the Corinth rift, Greece: Results from repeated Global Positioning System surveys between 1990 and 1995, J. Geophys. Res., 105(B11), 2560525625 .

Clarke P. J., Davies R. R., England P. C., Parsons B., Billiris H., Paradissis D., Veis G., Cross P. A., Denys P. H., Ashkenazi V., Bingley R., Kahle H.- G., Muller M.-V. and Briole, P. (1998). Crustal strain in central Greece from repeated GPS measurements in the interval 1989-1997, Geophys. J. Int., 135(1), 195-214, 1998.

Chouliaras G. (2009). Seismicity anomalies prior to the 13 December 2008, $M_{S}=5.7$ earthquake in central Greece, Nat. Hazards Earth Syst. Sci. 9, 501-506.

Dreger D. S., 2002. Time-Domain Moment Tensor INVerse Code (TDMT_INVC) Version 1.1.Berkeley Seismological Laboratory, pp. 18.

Dreger D. S., 2003.TDMT_INV: Time Domain Seismic Moment Tensor INVersion. International Handbook of Earthquake and Engineering Seismology, W. H. K. Lee, H. Kanamori, P. C. Jennings and C. Kisslinger (eds.), Vol. B, pp. 1627.

Dreger, D. S., and Kaverina A., 2000. Seismic remote sensing for the earthquake source process and nearsource strong shaking: a case study of the October 16, 1999 Hector Mine earthquake, Geophys. Res. 
Lett. 27, pp. 1941-1944.

Ganas, A., and Papoulia I., (2000). High-resolution, digital mapping of the seismic haxard within the Gulf of Evia rift, Central Greece using normal fault segments as line sources, Natural Hazards 22, 203-223.

Hatzfeld, D., Ziazia, M., Kemenzetzidou, D., Hatzidimitriou, P., Panagiotopoulos, D., Makropoulos, K., Papadimitriou, P. and Deschamps, A., 1999. Microseismicity and focal mechanisms at the western termination of the North Anatolian Fault and their implications for continental tectonics. Geophys. J. Int., 137, 891-908.

Kaverina A., Dreger D., and Price E., 2002. The Combined Inversion of Seismic and Geodetic Data for the Source Process of the 16 October 1999 Mw 7.1 Hector Mine, California, Earthquake, Bull. Seism. Soc. Am. 92, pp. 1266-1280.

Kiratzi A., 2002. Stress tensor inversions along the westernmost North Anatolian Fault Zone and its continuation into the North Aegean Sea. Geophys. J. Int., 151, 360-376.

Novotný O., Zahradník J., and Tselentis G.-A., 2001. North-Western Turkey earthquakes and the crustal structure inferred from surface waves observed in Western Greece. Bull. Seismol. Soc. Am., 91, pp. 875-879.

Roberts G. P. and Ganas, A. (2000). Fault slip directions in central and southern Greece measured from striated and conjugated fault planes: Comparison with focal mechanism and geodetic data, J. Geophys. Res., 105, 23443-23462.

Roumelioti, Z., Benetatos, C., Kiratzi, A. and Dreger D., 2008a. Near-real time moment tensors for earthquakes in Greece based on seismological data of the Hellenic Unified Seismological Network. 3rd National Conference of Earthquake Engineering and Engineering Seismology, Athens, 5-7 November, 2008, paper ID:1789.

Roumelioti,Z., Kiratzi, A. and Dreger D., 2008b. Near-Real Time Shake Maps for Earthquakes in Greece: pilot application. $3^{\text {rd }}$ National Conference of Earthquake Engineering and Engineering Seismology, Athens, 5-7 November, 2008, paper ID: 2105.

Roumelioti, Z., Kiratzi A. and Benetatos Ch. (2010). Time domain moment tensors of earthquakes in Greece and its surroundings for the years 2006-2007: the database of the Aristotle University of Thessaloniki, Journal of Geodynamics, in press.

Saikia C. K., 1994. Modified frequency-wavenumber algorithm for regional seismograms using Filon's quadrature; modeling of Lg waves in eastern North America. Geophys. Journ. Int., 118, pp. 142-158.

Skarlatoudis, A. A., Papazachos C. B., Margaris B. N., Theodulidis N., Papaioannou Ch., Kalogeras I., Scordilis E. M., and Karakostas V., 2003. Empirical peak ground-motion predictive relations for shallow earthquakes in Greece. Bull. Seism. Soc. Am. 93, pp. 2591-2603.

Skarlatoudis, A. A., Papazachos C. B., Margaris B. N., Theodulidis N., Papaioannou Ch., Kalogeras I., Scordilis E. M., and Karakostas V., 2007. Erratum to "Empirical peak ground-motion predictive relations for shallow earthquakes in Greece. Bull. Seism. Soc. Am. 97(6), pp. 2219-2221, doi: $10.1785 / 0120070176$.

Wald, D. J., and Allen T. I., 2007. Topographic slope as a proxy for seismic site conditions and amplification. Bull. Seism. Soc. Am. 97(5), pp. 1379-1395, doi: 10.1785/ 0120060267.

Wessel, P., and Smith, W.H.F., 1998. New improved version of the Generic Mapping Tools released. EOS Trans. AGU 79, 579. 